\title{
Processo de ensinar e aprender em UTI: um estudo fenomenológico*
}

\author{
The teaching-learning process in ICU: a phenomenological study \\ Proceso de enseñanza-aprendizaje en UCI: un estudio fenomenologico
}

\section{Glauteice Freitas Guedes', Conceição Vieira da Silva Ohara', Gilberto Tadeu Reis da Silval \\ 'Universidade Federal de São Paulo. Departamento de Enfermagem. São Paulo, SP}

Submissão: 30/06/2008

Aprovação: 12/11/2008

\section{RESUMO}

Este estudo teve como objetivo compreender o significado atribuído por docentes, durante os estágios de enfermagem em terapia intensiva, ao processo de ensinar e aprender. Trata-se de uma pesquisa Qualitativa fenomenológica. Os dados foram obtidos por meio de entrevista com a seguinte Questão norteadora: “Como você vivencia o processo de ensino-aprendizagem nos estágios de UTI?” Emergiram Quatro categorias abertas: "Um despertar para a UTI", "Uma busca de como ensinar Enfermagem em Cuidados Intensivos", "Um encontro entre docente e discente" e "Uma experiência significativa". A vivência com os alunos, apesar de despertar inicialmente medos e angústias por se aproximarem da morte e por prestarem cuidados aos pacientes críticos, permite o encontro docente/discente nesse ambiente, facilitando o processo de ensino-aprendizagem.

Descritores: Ensino; Educação em enfermagem; Unidades de terapia intensiva.

\section{ABSTRACT}

This study aimed to understanding the meaning attributed by teaching staff throughout the traineeship from nursing under graduation course in intensive care on the teaching and learning process. It's a study of phenomenological Qualitative approach. The data were obtained through the following guiding Question: "How do you live the teaching-learning process at the ICU traineeship?". From the subjects' descriptions, four open categories came up: "An awakening to ICU", "A searching for how to teaching Nursing in Intensive Care", "A connection between the teaching staff and the students" and "A meaningful experience". This study showed that this living experience, which is shared, permits an approaching and the meeting of the teaching staff with the students in this setting, facilitating the teaching-learning process.

Desxriptors: Teaching; Education, nursing; Intensive care units.

\section{RESUMEN}

Este estudio tuvo como objetivo comprender el significado atribuído por los profesores en las prácticas de enfermería en terapia intensiva sobre el proceso de enseñanza y aprendizaje. Se trata de una investigación cualitativa fenomenológica. Los datos fueron obtenidos a través de entrevistas con la siguiente pregrunta orientadora: ¿"Como usted vive el proceso de enseñanza-aprendizaje en las prácticas de UCI?" Surgieron cuatro categorías abiertas: "Un despertar para la UCl”, "Una busca de como enseñar enfermería en la UCI”, "Un encuentro entre profesor y alumno" y "Una experiencia significativa". La vivencia con el alumno, a pesar de despertar inicialmente miedos y angustias por la proximidad con la muerte y por prestar cuidados a pacientes críticos, permite el encuentro profesor/alumno en ese ambiente facilitando el proceso de enseñanza-aprendizaje.

Descriptores: Enseñanza; Educación en enfermería; Unidades de terapia intensiva. 


\section{INTRODUÇÃO}

A motivação para a realização deste estudo originou-se durante minha trajetória profissional como enfermeira docente no Curso de Graduação em Enfermagem, no ensino de enfermagem em cuidados intensivos. Nessa trajetória, Questionava-me sobre Qual a forma mais apropriada para ensinar os aspectos intensivos do cuidar aos estudantes de enfermagem. As preocupações em discutir conteúdos, estratégias, métodos e técnicas de ensino-aprendizagem e avaliação do processo permaneciam até o presente momento, levando-me a entender o Quê e como acontece o ensino dessa disciplina em Questão. Acredito ser importante refletir e compreender as atividades desempenhadas pelos docentes de enfermagem em Unidade de Terapia Intensiva (UTI), pois somos os responsáveis pelos programas da disciplina, pela elaboração de trabalhos científicos, pela preparação e apresentação das aulas, assim como o acompanhamento dos estudantes no campo de estágio.

Todo esse processo de ensinar e aprender é influenciado pela experiência do docente na sua relação com os discentes e pelo planejamento de ensino e a importância da participação ativa do estudante nesse processo, e para Que isso aconteça, torna-se necessário conhecer suas necessidades, expectativas e a realidade com a Qual ele vai trabalhar ${ }^{(1)}$. Assim, o docente é o principal mediador entre a motivação do discente e a aprendizagem Que precisa ser desenvolvida. É de responsabilidade do professor identificar os interesses do aluno, suas dificuldades e principalmente suas necessidades. Para compreender tal fenômeno, ele deve ser considerado com atenção, para Que se possa realizar um planejamento adequado aos vários aspectos, temas e estratégias de ensino, pertinentes ao processo de ensino-aprendizagem em UTI ${ }^{(2)}$.

Partindo dessa trajetória e desse contexto, Questiono-me a respeito da percepção dos docentes sobre o processo de ensinoaprendizagem nos estágios em UTI, com o intuito de explicitar como essa atividade se mostra para aqueles que a vivenciam. $\mathrm{O}$ propósito é aproximar-me do seu pensar e, a partir de seus discursos, poder desvelar perspectivas dessa prática, para então compreendê-la. Assim, o objetivo deste estudo é compreender o significado atribuído por esses docentes, durante os estágios do Curso de Graduação em Enfermagem em terapia intensiva, ao processo de ensinar e aprender na UTI.

\section{METODOLOGIA}

Ao propor a investigação no sentido de como se dá o ensino na terapia intensiva com o docente, pensei em ir além do mundo das aparências e dos conhecimentos teóricos e aproximar-me dessa experiência humana, para apreendê-la a partir do seu mundo-vida. Para tal, busquei um método Que possibilitasse a compreensão das perspectivas dos estágios Que cada docente vela em seu ser, em sua experiência vivida. Por isso, optei pela pesquisa Qualitativa fenomenológica, cuja proposta básica fundamenta-se na compreensão daQuilo Que se Quer estudar como fenômeno humano.

Os sujeitos da pesquisa foram os docentes de duas instituições de ensino, uma pública e outra privada, Que acompanham os estágios de enfermagem em UTI adulto. O número de participantes do estudo foi sendo configurado à medida Que se realizava a análise dos dados que emergiram das entrevistas, sendo esse número definido, portanto, pelas próprias descrições. Dessa forma, foram coletados seis discursos por meio da seguinte Questão norteadora: "Como você vivencia o processo de ensino-aprendizagem nos estágios de UTI?".

As entrevistas foram realizadas após a análise e aprovação dos Comitês de Ética em Pesquisa da Universidade Federal de São Paulo/ Hospital São Paulo - Parecer CEP no 0004/07 e da Faculdade Santa Marcelina - Parecer no 248/06. Precedendo cada início da entrevista, foi lido o Termo de Consentimento Livre e Esclarecido, garantindo dessa forma os preceitos éticos e legais envolvidos em pesQuisa com seres humanos, respeitando-se assim os aspectos ético-legais da Portaria 196/96 do Comitê Nacional de Pesquisas com Seres Humanos

Optamos pela gravação das falas dos sujeitos, por proporcionar maior liberdade do pesquisador para atentar às falas originárias, penetrar o mundo dos docentes e aproximar e compreender o fenômeno vivido e investigado. Foi permitido aos sujeitos participantes do estudo falarem livremente sobre o fenômeno, não sendo estabelecido tempo de duração, com o cuidado de não interferir durante sua fala, pois em Qualquer observação ou pergunta, poderia haver interferência no discurso espontâneo do sujeito. As entrevistas foram gravadas com as autorizações prévias e posteriormente transcritas, com o cuidado de manter na íntegra tudo o Que foi descrito pelos professores.

Após a coleta dos discursos e suas transcrições, procedemos à análise Qualitativa do fenômeno situado, Que está dividida em duas etapas importantes: a análise ideográfica e a análise nomotética.

A primeira etapa, análise ideográfica, teve início com as transcrições dos discursos, em Que estabeleci um contato direto com o fenômeno vivido, por meio de uma leitura cautelosa de todos os discursos. Cada discurso, identificado pela letra D, foi submetido a uma re-leitura e depois foram destacadas as Unidades de Significado (US), tendo sempre em mente a Questão norteadora deste estudo. Por meio dessa análise, foi possível ter uma visão global do discurso, iluminando os significados encontrados. A segunda etapa, análise nomotética, é a análise da totalidade dos discursos em Que ocorre o cruzamento entre as unidades de significado e uma reflexão sobre a estrutura geral do fenômeno. Neste momento, começaram a se esboçar as primeiras generalidades, apresentando os aspectos comuns entre os discursos, o Que permitiu Que o fenômeno se desvelasse.

\section{RESULTADOS E DISCUSSÃO}

\section{Construindo Caminhos a partir da Compreensão Temática}

As convergências Que revelam o significado a partir da estrutura do fenômeno processo de ensinar e aprender em enfermagem em cuidados intensivos permitiram agrupar os depoimentos em Quatro categorias abertas: Um despertar para a UTI, Uma busca de como ensinar Enfermagem em Cuidados Intensivos, Um encontro entre docente e discente e Uma experiência significativa.

\section{Tema 1 - Um Despertar para a UTI}

Para esse tema, convergem as unidades de significado Que descrevem a percepção Que os docentes têm ao adentrarem o ambiente de terapia intensiva com os alunos, suas dificuldades de ensinar, seus sentimentos perante as situações educativas e as 
experiências Que os alunos adQuirem durante todo o seu processo de formação até aQuele momento.

O docente revela Que a unidade de terapia intensiva, como ambiente para o ensino de enfermagem aos pacientes críticos, desperta muito interesse por parte dos alunos, por ser uma unidade Que apresenta a possibilidade de várias práticas de enfermagem básicas e específicas, pela sua complexidade e pelo aparato tecnológico como recurso para sobrevida dos doentes internados. Por esse início ser muito intenso, eles se sentem desorientados. Podemos observar pelas falas que seguem:

... a unidade de terapia intensiva, na verdade, é uma unidade em Que desperta bastante interesse de todos os alunos, por ser uma unidade de alta complexidade e com bastante avanço tecnológico... (D2USI)

...no começo, até ele se ajustar na unidade, ele fica meio perdido. (D2US3)

Percebe-se nos depoimentos dos docentes Que o mundo da UTI contém elementos importantes Que facilitam e apóiam as atividades de ensino e aprendizagem dessa disciplina. O ensino fundamenta-se na estimulação, na motivação e no interesse, Que são favorecidos por recursos Que facilitam a aprendizagem. Por ser a UTI um ambiente complexo e de alta tecnologia ${ }^{(3)}$, desperta a curiosidade, e por conseqüência disso, o aprendizado. Com a descoberta do mundo, o professor percebe que o aprender do aluno é algo Que se revela como aquilo acontece e Que vem ao encontro, e nos fascina, enredando o ser na dialética viva da oposição homem-mundo. O aprender ocorre somente Quando o indivíduo depara com situações reais, um esclarecimento acerca do vivido, de seus encaminhamentos, de suas Questões, de suas respostas e fracassos ${ }^{(4)}$. Assim também ocorre no processo de ensino-aprendizado nos estágios de terapia intensiva.

As dificuldades também estão presentes e expressas expressas pelos docentes como enfrentamento do desgaste físico e mental, dos desafios e obstáculos para ensinarem enfermagem em cuidados intensivos, pela falta de preparo dos alunos nas disciplinas consideradas básicas e fundamentais no início de sua formação e pela própria complexidade dos pacientes internados na terapia intensiva.

...mas a gente tem muitos problemas, aluno problemático, também alunos trabalhadores, não são muitos, mas a gente tem alguns alunos Que têm problemas familiares, alunos com problemas emocionais, vários Que a gente tem que lidar no meio do caminho... (D4US3I)

Essa dificuldade pode ser minimizada, se o docente trabalhar com um planejamento cuidadoso e objetivo do plano de ensino da disciplina de enfermagem em cuidados intensivos. O conhecimento e a compreensão desses fatores devem ser considerados com atenção, para Que, por meio de um planejamento adequado, os vários aspectos do tema possam ser analisados pelos docentes e discentes em suas experiências na UTI.

Nas convergências dos vários depoimentos, os docentes descrevem a sua experiência ao depararem com os alunos na UTI Que expressam sentimentos de ansiedade e temor diante do desconhecido.
Esse sentimento é próprio do nosso modo de ser-no-mundo, especialmente em situações consideradas novas e desafiadoras e a aproximação da morte e o medo se fazem presentes nas falas dos docentes. Percebemos tais sentimentos nas seguintes falas:

\section{...coloca de frente com a morte é algo de extrema responsabilidade...(D3US9)}

...nos primeiros dias alguns anos atrás eles mal conseguiam piscar, Que era uma coisa tão diferente para eles, era uma sensação acho muito estressante, Que eles mal conseguiam realmente dominar as coisas, fazer as coisas, muito medo, percebíamos isso.(D4US8)

O cuidar do outro em UTI mobiliza sentimentos, portanto as experiências vivenciadas pelos alunos durante os estágios envolvem uma dimensão emocional Que deve ser considerada pelos professores. Alguns autores sugerem Que os professores reflitam sobre estratégias que possam minimizar os desconfortos dos alunos com o intuito de facilitar seu desenvolvimento integral ${ }^{(5)}$.

\section{Tema 2 - Uma Busca de Como Ensinar Enfermagem em \\ Cuidados Intensivos}

No caminho para desvelar suas experiências no processo de ensino-aprendizagem no estágio de UTI, os docentes expressam suas preocupações relacionadas ao Que ensinar da assistência de enfermagem em unidades de terapia intensiva, Quais os propósitos Que devem ser definidos para essa ação educativa e Quais as estratégias para alcançar o melhor resultado na sua própria formação de enfermeiro intensivista.

Transparece nos discursos Que as ações docente e discente ocorrem em função dos objetivos Que devem ser alcançados e Que é uma fase do processo de ensino-aprendizagem indispensável para o trabalho do professor. Os objetivos educacionais traduzem os propósitos definidos de maneira explícita Quanto ao desenvolvimento das Qualidades, capacidades e habilidades que os discentes precisam para se capacitar ${ }^{(6)}$. Podemos observar isso na fala Que segue:

...se tivermos claro os objetivos da disciplina, a gente também vai saber até onde a gente consegue desenvolver ... (D6US27)

Percebemos nos discursos dos docentes uma tênue preocupação em romper a dicotomia entre teoria e prática. Frente à diversidade de situações clínicas oriundas de campo de estágio, se faz necessária a associação teórico-prática no processo de ensinar e aprender.

...mas não pode ficar restringido somente à técnica se você não tiver essa junção com a teoria, porque perdeu o estágio. (D3US5)

Ao olhar o processo de ensinar e aprender na UTI, a essência desse fenômeno desvelou-se numa busca do docente de como ensinar enfermagem em cuidados intensivos. O docente nos transmite sua preocupação em ter objetivos claros e bem definidos no momento em Que adentra a UTI e percorre todas as etapas do processo, passando pela associação da teoria e prática, buscando 
estratégias para atingir suas metas e, por fim, avaliar a aprendizagem. Vejamos nas falas Que seguem:

...com a diminuição de alunos por docente, dentro da unidade de terapia intensiva, dentro das unidades com maior complexidades, acredito Que tenha melhorado tanto a Questão do ensinar pelo docente Quanto pelo aprender pelo aluno. (D2US5)

...eu procurava e achava que dava, Que sempre surtia efeito, sempre fazer uma demonstração junto. (D3USI I)

Outro fator importante notado nos dicursos é a busca dos docentes por um modelo de ensino diferenciado e adequado para a época em Que vivemos. O ensino de enfermagem em cuidados intensivos ainda está voltado para uma abordagem tradicionalista, em Que o ensino está centrado no docente e voltado para os aspectos externos do processo, como estratégias de ensino e planejamento. Entretanto, de acordo com os docentes, esse modelo tende às transformações exigidas por um mundo cada vez mais informatizado e competitivo.

...estamos, na medida do possível, tentando sair das aulas tradicionais nas salas de aulas para uma atividade um pouQuinho mais dinâmica, ou em laboratório ou utilizando aulas práticas com simulações ou então em aula teórica em sala de aula, procurando fazer alguma dinâmica Que consigam a participação melhor dos alunos ou é um estudo dirigido. Ou algum exercício Que ele tenha que resolver no ato ou algum exercício que ele tenha Que nós entregamos com antecedência para eles, mas marcamos uma data para Que eles apresente a solução do exercício para o colega e a gente apresente em grupos pequenos ...(D6USII)

Madeira e Lima ${ }^{(7)}$ afirmam Que há novas demandas para o ensino e aprendizagem no campo da enfermagem e elas apontam para uma perspectiva Que exige o abandono do modelo de ensino tradicional, possibilitando a formação crítica e reflexiva dos profissionais e caminhando para uma mudança da postura do docente para o aprender a aprender e aprender a ensinar.

Estudos nos mostram Que está ocorrendo um movimento de avanço da reflexão sobre o ser professor. Vale ressaltar Que esse processo está em constante construção e decorre, em grande parte, de influências recebidas durante sua própria história, sua formação acadêmica e de experiências profissionais com outros professores e alunos. Assim, podemos afirmar Que a formação docente é um processo de construção e reconstrução constante.

$\mathrm{Na}$ convergência dos discursos dos docentes, emergem seus pensamentos acerca da sua formação de educador de enfermagem em cuidados intensivos. Para os depoentes, é importante que o professor tenha experiência como enfermeiro assistencial na UTI, para Que consiga conduzir o estágio com segurança e tornar o processo de aprendizagem mais fácil para o aluno.

... a Questão da dificuldade do aluno é bastante contornada se a gente tiver um docente bastante esclarecido da situação, um docente seguro das ações Que ele tem sob seu controle ali na unidade... (D2US8)

...eu acho importante o professor ter vivência na área como enfermeiro assistencial, eu acho que acaba contribuindo mais, não sei posso estar errada, né? Então, todas nós Que estamos com o doente, a gente tem pelo menos, minimamente alguns anos de experiência, algumas mais outras menos, mas é isso Que a gente tem percebido... (D4US32)

As unidades de significado extraídas dos discursos dos docentes dão validade a alguns estudos Que nos mostram as competências do docente universitário e destacam o domínio de determinado conhecimento $^{(8,9)}$, ou seja, o domínio de sua área de formação técnica específica. Entretanto, estudos nos mostram outras competências, não citadas diretamente pelos docentes: domínio na área pedagógica e o exercício da dimensão política ${ }^{(10-12)}$.

Deve ser feita uma reflexão sobre a prática de Quem ensina no cotidiano da enfermagem, pois o docente utiliza conhecimentos da pedagogia para ações educativas e, para isso, deve ter um preparo condizente.

Pesquisas nos mostram trabalhos realizados para o crescimento e reconstrução de uma prática educativa do enfermeiro-professor por meio da implantação de disciplinas voltadas para a formação docente na área da saúde e a criação de espaços para a reflexão de sua prática. Essa atividade tem como objetivo primordial gerar mudanças importantes na Qualidade do ensino superior e mesmo de maneira lenta e progressiva, vem trazendo bons resultados ${ }^{(13)}$.

\section{Tema 3 - Um Encontro entre Docente e Discente}

A relação estabelecida entre professores e alunos constitui uma das partes essenciais do processo de ensino e aprendizagem. QualQuer forma de comunicação, os aspectos afetivos e emocionais, a dinâmica das expressões nas atividades práticas do estágio são fatores envolvidos nessa relação.

Corroborando Pinho e Santos ${ }^{(14)}$, percebemos que ao longo do estágio de UTI, a relação professor e aluno é fortalecida, pois o professor transmite aos alunos contribuições e aprendizados de vida pessoal e profissional, além de aprender com eles Que as pessoas pensam e agem de maneiras diferentes, despertando para uma consciência mais crítica e facilitadora do processo de ensinoaprendizagem.

... nós estamos muito próximas dos alunos... (D4US I6)

...a gente fica muito próxima do aluno, muito presente, dá segurança ao aluno, mas ao mesmo tempo, a gente também procura deixá-lo realmente participar da assistência, ele assume, o aluno assume o doente grave... (D4USI 7 )

Na terapia intensiva, nós sempre privilegiamos grupos pequenos para favorecer uma melhor proximidade entre professor e aluno, para que ele possa ser atendido pelo professor em todas as suas necessidades, porQue o aluno de graduação Quando entra em terapia intensiva, a Quantidade de equipamentos, dispositivos novos é muito grande, então, precisa ter um docente que tenha condições de atender todas as necessidades do aluno, para que ele proporcione ambiente favorável para o aprendizado dele. 
(D6US3)

Outro ponto a ser considerado é que o sucesso ou não da aprendizagem está fundamentado essencialmente na afetividade, na confiança, na empatia e respeito entre alunos e professores, alunos e alunos, professores e professores ${ }^{(15)}$. Tais fatores podem facilitar o processo de ensino-aprendizagem, tornando o professor um facilitador.

A relação entre educador e educando estimula e ativa o interesse do aluno, assim o professor apresenta duas formas básicas na sua relação com o aluno: a de incentivador e orientador ${ }^{(16)}$. Dessa forma, a relação professor e aluno nos estágios é considerada como algo presente e positivo, possibilitando que o docente consiga compreender o aluno como um ser no mundo e com o outro na terapia intensiva.

Carvalho ${ }^{(17)}$ enfatiza a importância de o professor interativo ter como característica marcante voltar-se para a interação, estando mais próximo dos estudantes, pois prioriza uma relação mais afetiva e aberta. Com esse tipo de relação professor-aluno, pode ser observado nos estudantes maior interesse, pois prestam atenção à fala do docente e participam efetivamente dos estudos e trabalhos realizados, sobretudo, porque perguntam e interagem mais de perto com o docente.

Com relação aos docentes, eles se consideram como facilitadores do processo de ensino e aprendizagem, uma vez Que estão próximos dos alunos durante o desenvolvimento de habilidades específicas dentro da UTI e, ainda, contribuem no levantamento de problemas e soluções de enfermagem junto à equipe multiprofissional.

A prática na UTI propicia um contato constante entre o aluno e o professor, favorecendo uma proximidade com o outro e uma individualização do ensino, pois o docente tem a possibilidade de trabalhar de acordo com as atividades, necessidades e potencial de cada discente. Para Que isso aconteça, torna-se necessário que o docente esteja preparado e constantemente atualizado.

\section{Tema 4 - Uma Experiência Significativa}

Os docentes descrevem a sua experiência vivida ao depararem com o processo de ensinar e aprender nos estágios de UTI, expressando sentimentos de satisfação em seu fazer docente e coragem para seguir ensinando enfermagem em terapia intensiva.

No cotidiano desses professores na terapia intensiva, encontramse situações Que favorecem o aprendizado do aluno, pois a UTI é considerada um campo que proporciona vivências importantes para a prática do enfermeiro, o Que torna para o docente uma experiência de aprendizado significativa.

Os participantes da pesquisa expressam Que os estágios na terapia intensiva constituem uma tarefa difícil de ser realizada, mas Que deve ser encarada como algo a ser superado e, ao mesmo tempo, como algo estimulador em suas atividades. Tais relatos podem ser observados nos discursos que seguem:

...tem muitos desafios, tem muitos obstáculos. Muitas vezes, a gente sente perdida frente às dificuldades dos alunos, a grande complexidade do paciente também. (DIUS2)

...não é muito fácil esse processo de assimilar e desenvolver essa coisa do raciocínio clínico...(D4US20) ...é desafiador... (D4US2)

...estimulante também... (D4US3)

...é estimulante para o gente porQue a gente pega esse aluno extremamente ingênuo do ponto de vista de como prestar assistência... (D4US22)

O professor expressa sentimento de satisfação por ensinar enfermagem em terapia intensiva. No processo de ensino e aprendizagem vivenciado pelo docente emerge o seu gosto por ensinar, pois além de perceber o crescimento do aluno, ele depara com o seu próprio aprendizado. Vejamos no depoimento abaixo:

...é uma experiência muito gratificante, em virtude, do próprio crescimento Que a gente tem, tanto Quanto pelo professor Quanto pelo crescimento do aluno. (DIUSI)

Ao vivenciar o ensinar e o aprender na terapia intensiva, os docentes relatam Que esse processo na UTI é intenso, por proporcionar muitas oportunidades para os alunos realizarem procedimentos de enfermagem e situações Que propiciam as discussões com o grupo sobre suas atividades relacionadas aos pacientes graves. Dessa maneira, esse processo possibilita experiências significativas de aprendizado.

...é bastante intenso, porque tem muitas oportunidades e o aluno acaba tendo várias opções para aprender. (D2US2)

...naquele ambiente ele tem oportunidade de exercitar o raciocínio lógico, desenvolver habilidades, desenvolver a comunicação com os outros membros da equipe, desenvolver um trabalho em grupo... (D6USI6)

Talvez essa experiência significativa durante os estágios de UTI possa estar atrelada ao fato de os alunos valorizarem mais uma simples observação em um ambiente real do Que um tempo de ensino teórico-prático em ambiente artificial, como a sala de aula ou o laboratório de enfermagem. Por mais Que os alunos possam expressar algum tipo de insegurança, eles parecem estar mais entusiasmados para a realização dos estágios do Que as aulas teóricas ${ }^{(18)}$. Esse momento de entusiasmo contribui de maneira significativa para o processo de ensinar e aprender, e o docente deve ter a sensibilidade de captar e transformar tal sentimento em motivação para o aprendizado, despertando no aluno o desejo de aprender, tornando esse momento uma experiência significativa.

Assim, os estágios de enfermagem em cuidados intensivos estão representados como um dos papéis essenciais para a associação do cuidado aos pacientes graves; no entanto não há manuais com fórmulas rígidas. $\mathrm{O}$ cuidado em terapia intensiva em toda sua amplitude precisa ser entendido como um processo interativo entre professor-aluno, teoria-prática, portanto, deve ser vivido ${ }^{(19)}$.

\section{REFLETINDO SOBRE O ESTUDO}

Pensando como docente de enfermagem no mundo-vida em cuidados intensivos e refletindo sobre discursos dos sujeitos a partir 
do desvelar do fenômeno, é Que o fazer docente mostra-se e explicita o processo de ensinar e aprender dentro da UTI. Dessa forma, apresentamos aQui uma primeira leitura hermenêutica do presente estudo.

Durante a trajetória desta pesquisa e buscando adentrar esse processo, vi-me diante de uma interrogação sobre a Questão "ser" docente na UTI. Esse "ser" para Heidegger é a maneira como alguma coisa se torna presente, manifesto, entendido, percebido, compreendido e finalmente conhecido para o ser humano, para o "ser-aí"(20).

Os discursos permitiram apreender Que o docente em seu caminhar na UTI fosse realmente entendido, percebido como seraí preocupado com o ensino e, principalmente, com a aprendizagem.

Os discursos revelaram um mundo a partir do olhar do docente preocupado com o discente ao adentrar a UTI, pois é uma unidade Que desperta certa ansiedade e medo de ambas as partes, e ao mesmo tempo, aguça a curiosidade para um universo tecnológico e extremamente complexo como é a UTI.

Ao olhar para o mundo do processo de ensino-aprendizagem na UTI, a essência desse fenômeno desvelou-se numa busca do docente de como ensinar enfermagem em cuidados intensivos. A essência, segundo Heidegger, relata o mundo do outro. E no momento em Que o docente nos transmite sua preocupação em ter objetivos claros e bem definidos, ao adentrar com os alunos esse contexto e percorrer todas as etapas do processo, é evidenciada uma preocupação relacionada com sua própria formação como enfermeiro-docente intensivista e a aproximação entre discente e docente como um facilitador no processo de ensino e aprendizagem.

Com essa aproximação, torna-se necessário apreender o ser-aí em termos de sua existência nesse processo, cuja Questão tem início com o aspecto ôntico do ser-aí, solicitando a compreensão em termos de sua temporalidade. A estrutura fundamental do docente como ser-aí no processo de ensinar e aprender revela-se como a de um ser no mundo.

Para Heidegger, o ser-no-mundo são as múltiplas maneiras que o homem vive e pode viver, os vários modos de como o homem se relaciona e atua com os entes Que encontra e a ele se apresentam. Para a compreensão da existência do ser-aí-no-mundo, é preciso analisar a existência cotidiana, ou seja, estar sempre no mundo e com os outros, pois existir é ser-no-mundo-com-os-outros, o que permite dizer Que é sempre pessoal essa existência, porém situada num contexto de outros.

O mundo das relações é o Que vivemos, este é um constitutivo humano, pois não existe um ser sozinho, sempre dependemos de alguma coisa e de alguma circunstância. O docente de enfermagem em cuidados intensivos tem sua existência enquanto ser-aí-nomundo dependente das suas relações com o ambiente de UTI e com outras pessoas (pacientes, discentes e profissionais), portanto sua existência é uma existência compartilhada.

Essa existência compartilhada é o Que traz para o processo de ensino-aprendizagem algo como a satisfação, estímulo e oportunidade de ensinar e aprender a assistência de enfermagem aos pacientes gravemente enfermos. Além disso, permite a aproximação e o encontro do docente com o discente nesse ambiente, facilitando o processo de ensino-aprendizagem.

Toda essa vivência com os alunos durante os estágios proporciona ao docente a reflexão sobre todo esse processo, permitindo Que cada participante tenha como resposta em sua vida profissional uma experiência significativa.

Essa experiência imbrica em uma Questão muito importante para o processo de ensino-aprendizagem: a relação do homem com os outros homens.

O relacionar-se com alguém numa maneira envolvente e significante é chamado de solicitude, Que apresenta características básicas do ter consideração para com o outro e de ter paciência com o outro ${ }^{(21)}$. Essas duas características não são consideradas princípios morais, mas incorporam a forma como se vive com o outro, por meio das experiências e expectativas que cada um tem de si.

Os discursos permitiram revelar da solicitude existente entre alunos e docentes. Acredita-se Que a partir dessa solicitude existente, como uma oportunidade de aproximação, é Que a educação deve ser pensada e trabalhada.

Essa trajetória nos permite compreender a amplitude do fazer docente. Ela evidencia Que o ensinar em cuidados intensivos não deve ficar restrito apenas aos conhecimentos técnico e científico, ela deve contribuir significativamente na formação de um ser humano que cuida do outro em momentos difíceis da vida.

Por fim, entendemos Que este trabalho, por ser uma primeira leitura hermenêutica, abre caminhos para sua continuidade, atendendo a uma exigência dos estudos fenomenológicos hermenêuticos e ensejando uma análise mais abrangente sobre a temática aQui estudada.

\section{REFERÊNCIAS}

1. Dilly CML, Jesus MCP. Processo educativo em enfermagem das concepções pedagógicas à prática profissional. São Paulo: Robe Editorial; 1995.

2. Zago MMF, Sawada NO, Casagrande LDR. As expectativas dos alunos de enfermagem Quanto à unidade de ensino "a assistência de enfermagem ao paciente de terapia intensiva". Rev Esc Enferm USP 1991; 25(1): 1 13-20.

3. Lino MM, Silva SC. Enfermagem na unidade de terapia intensiva: a história como explicação de uma prática. Rev Nursing 2001 ; 41(4):25-9.

4. Fonseca AS. O estudo de caso: o significado para os discentes de enfermagem [tese]. São Paulo: Universidade Federal de São Paulo; 1999.

5. Casate IC, Corrêa AK. Vivências de alunos de enfermagem em estágio hospitalar: subsídios para refletir sobre a humanização em saúde. Rev Esc Enferm USP 2006; 40(3):32 I-8.

6. Libâneo JC. Didática. São Paulo(SP): Cortez; 1994.

7. Madeira MZA, Lima MGSB. A prática pedagógica das professoras de enfermagem e os saberes. Rev Bras Enferm 2007; 60(4): 400-4.

8. Maciel AF, Silva GTR, Guedes GF. Enfermagem: uma abordagem fenomenológica pela escolha profissional. In: Anais do III Seminário Internacional de Pesquisa e Estudos Qualitativos e V Encontro de Fenomenologia e Análise do Existir. Jun, 1-3, 2006. São Paulo (SP), Brasil. São Paulo: Sociedade de Estudos e Pesquisa Qualitativos - SIPEQ; 2006. p. 42. 
9. Freitas MAO, Seiffert OMLB. Formação docente e o ensino de pós-graduação em saúde: uma experiência na UNIFESP. Rev Bras Enferm 2007; 60(6): 335-40.

10. Pimenta SG, Anastasiou LGC. Docência no ensino superior. São Paulo: Cortez; 2002.

11. Behrens MA. A formação pedagógica e os desafios do mundo moderno. In: Masetto MT (org). Docência na universidade. Campinas: Papirus, 1998.

12. Mota DDCF, Kimura M. Reflexões sobre o preparo para a docência na pós-graduação em enfermagem. Rev Esc Enferm USP 2007; 4I(I):161-4.

13. Rodrigues MTP, Mendes Sobrinho IAC. Enfermeiro professor: um diálogo com a formação pedagógica. Rev Bras Enferm 2007; 59(3): 456-9.

14. Pinho LB, Santos SMA. Estágio de docência em enfermagem psieuiátrica: uma experiência durante a pós-graduação. Rev Gaúcha Enferm 2006; 27(2):176-84.

15. Faria JIL, Casagrande, LDR. A educação para o século XXI e a formação do professor reflexivo na enfermagem. Rev Latinoam Enfermagem 2004; 12(5):82 1-7.

16. Shimizu HE, Ciampone MHT. Sofrimento e prazer no trabalho vivenciado pelas enfermeiras Que trabalham em unidades de terapia intensiva em um hospital escola. Rev Esc Enferm USP 1999; 33(1): 76-105.

17. Carvalho MVB. Um estudo etnográfico realizado nas salas de aula no ciclo básico nos cursos de enfermagem e medicina e a prática pedagógica do docente. Texto Contexto Enferm 1999; 8(1): 257-72.

18. Saupe R. O cotidiano de ensinar e aprender enfermagem. Rev Gaúcha de Enfermagem 1994; 15(1/2):27-33.

19. Nunes CB, Silva CV, Fonseca AS. Ouvindo as mães sobre a consulta de enfermagem a seus filhos. Acta Paul Enferm 2003; 16(3):31:40.

20. Heidegger $M$. Todos nós... ninguém: um enfoque fenomenológico do social. São Paulo(SP): Moraes; 1981. 